\title{
Evaluation on effectiveness of learning linear algebra using gamification
}

\author{
Rini Hafzah Abdul Rahim ${ }^{1}$, Aslina Baharum ${ }^{2}$, Hanafi Hijazi ${ }^{3}$ \\ ${ }^{1,2,3}$ Faculty of Computing and Informatics, Universiti Malaysia Sabah, Malaysia
}

\begin{tabular}{l}
\hline \hline Article Info \\
\hline Article history: \\
Received Jan 9, 2019 \\
Revised Mar 2, 2019 \\
Accepted Mar 18, 2019
\end{tabular}

\section{Keywords:}

Gamification

Linear algebra

Polytechnic

Quantitative

\begin{abstract}
This study evaluate effectiveness of learning Linear Algebra using gamification strategy. In this study, gamification with storytelling strategy is used as teaching tools to attract student to learn Linear Algebra. This study using Polytechnic Malaysia syllabus with focus group of Diploma students for semester three (Mechanical Engineering) and semester four (Electrical Engineering) for two topics; Matrix and Numerical Method. They are five methods of calculation simultaneous linear equations which is 'Inverse', 'Cramer's Rule', 'Gauss Elimination', 'Lower Upper Doolittle' and 'Lower Upper Crout'. They are three main phases to develop this gamification; Pedagogy Phase, Design Phase and Evaluation Phase. Mixed methods approach combining quantitative (survey) and qualitative (Electroencephalogram) is used to evaluate students learning process using Linear Algebra gamification application. The findings of the five items surveyed showed that the acceptance of the prototype of the Linear Algebra Gamification Application was very encouraging from a total of 104 students. This is because all 38 questions for the five items earn a median of four and this indicates the majority of students choose "Agree" and "Strongly Agree". The findings also show the percent "Agree" and "Strongly Agree" for all questions having a high percentage of between 61.5 and 94.2. This shows more than half satisfied and likes to use the Linear Algebra Gamification Application prototype. With the development of the Linear Algebra Gamification Application prototype, it is hoped that the use of learning based can be extended to a variety of subjects as well as topics to make the learning process more interesting and fun as well as helping to motivate students to learn.
\end{abstract}

Copyright $@ 2020$ Institute of Advanced Engineering and Science. All rights reserved.

\section{Corresponding Author:}

Aslina Baharum,

Faculty of Computing and Informatics,

Universiti Malaysia Sabah,

88400 Kota Kinabalu, Sabah, Malaysia.

Email: aslina@ums.edu.my

\section{INTRODUCTION}

Gamification strategy is able to transform such a boring learning process into more engaging learning. This is because different gamification strategies will have different impacts on students [1]. In addition, learning using a gamification approach can create and enhance interactivity, engagement, encourage positive behavior, encourage students to study and develop their knowledge [2]. This positive development has been proven from previous studies showing that gamification learning can increase motivation and student involvement rather than traditional learning methods [3]. Now, learning using the gamification Gamification strategy is able to transform such a boring learning process into more engaging learning. This is because different gamification strategies will have different impacts on students [1]. In addition, learning using a gamification approach can create and enhance interactivity, engagement, 
encourage positive behavior, encourage students to study and develop their knowledge [2]. This positive development has been proven from previous studies showing that gamification learning can increase motivation and student involvement rather than traditional learning methods [3]. Now, learning using the gamification approach has begun to be introduced at the Primary, Secondary and Higher Education Institutions. Research shows that various fields have started implementing gamification learning such as STEM [4], Early Child Education [5], Language [6], Linus [7], Mathematics [8-10], Mental [11] Medicine [12], Physics [13], Culture [14] and History [15]. This is because, gamification is one of the teaching tool that implement $21^{\text {st }}$ century learning which is changed from educator-centred learning to student-centred learning [16]. Student-centred for teaching and learning, encourages students to actively engage, collaborate and enhance interpersonal skills in solving assignments provided by educators [17]. Currently, they are a few research that implementing gamification for mathematics. One of them is Monkey Revenge focus for Grade Eight students to learn Coordinate Geometric. Students need to help characters solve the Geometric Coordinate problem to advance to the next stage of storytelling. As a result of usage by 297 students, students are more satisfied with learning using gamification learning [18]. Another example is gamification for the purpose to increasing student involvement for Mathematics workout series by using game mechanics such as coin collection and guidance [19]. From this two example, gamification development for subject mathematics is still low especially for topics Linear Algebra. Mathematics is often considered difficult and complicated subjects by students. The difficulty experienced by the students causes students not to study Mathematics. There are various topics that students find difficult, including the topics of Algebra Linear [20]. Students regard Linear Algebraic topics as difficult as students have a weak base for Algebra Linear topics [21]. This makes it difficult for students to understand and master the entire Linear Algebra topic. At the same time, Mathematics is often regarded as unattractive and scary subjects [22]. This problem becomes more alarming when there are students who decide to leave school because they do not like Mathematics [23]. As the result, students who have difficulty in learning Mathematics will being demotivated and will further reduce the number of students pursuing Mathematics subjects. Motivation of a weak student should be enhanced by giving stimulus to enable them not to continue giving up and feeling inferior. Among the activities that can stimulate student motivation is to diversify teaching and learning pedagogy and approaches by conducting game activities that can encourage students to learn in fun and competing ways to become winners [24]. Therefore, it is extremely appropriate to develop Mathematical gamification on Algebra Linear topics to inculcate students 'interest in learning Algebra Linear by providing a variety of difficulty and multi-tasking gamification as they are compatible with the diversity of students' abilities and understanding.

This paper present evaluation on effectiveness of learning Linear Algebra using gamification. Evaluation phase shown findings of the five items surveyed showed that the acceptance of the prototype of the Linear Algebra Gamification Application was very encouraging from a total of 104 students. This is because all 38 questions for the five items earn a median of four and this indicates the majority of students choose "Agree" and "Strongly Agree". The findings also show the percent "Agree" and "Strongly Agree" for all questions having a high percentage of between 61.5 and 94.2. This shows more than half satisfied and likes to use the Linear Algebra Gamification Application prototype. With the development of the Linear Algebra Gamification Application prototype, it is hoped that the use of learning based can be extended to a variety of subjects as well as topics to make the learning process more interesting and fun as well as helping to motivate students to learn.

\section{METHODOLOGY}

They are a few process involved for research methodology, which is giving briefing and introduction to students, students fill up consent form, students answer pre-test question, learning process by using traditional or gamification, students answer post-test question, qualitative by using EEG, quantitative by using survey and result analysis by using Statistical Packages for Social Science. Process will be started with 10 minutes for briefing and consent form. After that, students will be given 15 minutes to answer pre-test question and next students can start theirs learning process by using traditional or gamification method. After student complete learning process they must answer post-test. During learning process and post-test students are required to use EEG device to collect their information by using mobile apps Effective Learning. Before student can complete data collection, students for gamification learning category must answer survey for Linear Algebraic Gamification Application. Participant involved 104 student at Kota Kinabalu Polytechnic that consists of 43 female students and 61 male students. For the purpose of Evaluation process by using quantitative method, only required students for Gamification Learning Category. 
The survey or questionnaire adapted by [25] is divided into two parts: Part A: Information and student background and Part B: The prototype of the prototype gamification Algorithm Gamification Application. Part B is rated using a Likert Scale that has five scales to evaluate all five Prototype Linear Algebraic Application prototypes. The five scales are 1: Extremely Disagreeable, 2: Disagree, 3: Undecided, 4: Agree and 5: Strongly Agree. The findings were analyzed using Median and Mod, for each item of gamification. The first gamification item is considered an Experience item, as a whole this item assesses the experience gained from the use of the Application of Application Linear Algebraic Gamification Application. 'Experience Factors', 'Mechanics', 'Rewards', 'Goals' and 'Social'. The first element evaluated for Version Two is Experience. Among the elements are achievement, autonomy, challenge, efficiency, curiosity, learning/mastery, user engagement with results, emotionally sensitive, goals, relevance and focus. The second element assessed for the Mechanical System. Among the elements are collecting, behavioral records, feedback, regular rules, nurturing/growth, unpredictable player effort, storytelling, shock and joy, time pressure and variable outcomes. The third element assessed for the Reward. Among the elements are rewards, real rewards, intangible rewards, progress, points, levels, badges/achievements. The next element, is the Goal. Among the distinguished elements are like clear goals, challenges/quest/missions/tasks and tasks that can be solved. The last elements that are available to Social. Among the elements are competition, leaderboard, collaboration, group work, fame/attention, social involvement loop and social incentives.

\section{RESULTS AND ANALYSIS}

The questionnaire adapted by [25] is divided into two parts: Part A: Information and student background and Part B: The prototype of the prototype Algorithm Gamification Application. Figure 2 shows information for student gender and race. Figure 1 shows students divided into 61 male students and 43 female students. This shows that more male students are involved in the gamification learning test than these girls are because boys prefer to play gamification compared to girls. Information for the nation consists of 61 students comprising of other races and 36 Malay students. This indicates that the majority of the students are Borneo residents of Bajau, Idahan, Dusun, Kadazan, Sino Dusun, Murut, Bisaya, Bugis and Brunei. Meanwhile, for age information, 60 students consisted of 20 years old, 16 students aged 21 years and 16 students aged 19 years. This shows that the highest respondent is 20 years old who is a Sijil Pelajaran Malaysia learner. Figure 2 shows information for student Mathematics grades their interest in Mathematics.

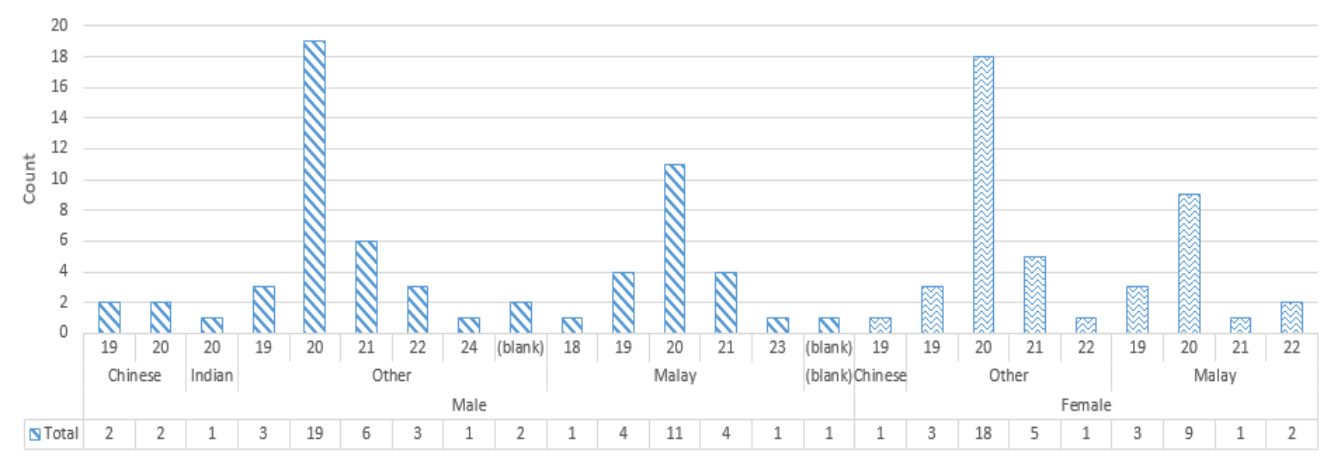

Figure 1. Student information for gender and race

Figure 2 shows student information on Mathematics grades students have earned in the last semester and their interest in Mathematics. A total of 26 students obtained grade $\mathrm{C}$ and 15 students obtained grade B. This indicates that the majority of students have a moderate achievement in Mathematics grade C. The findings for students' interest in studying Mathematics showed that 55 students were interested in studying Mathematics. This shows that more than half of students have a high interest in Mathematics subjects although these subjects are often considered to be difficult among students. Figure 3 shows student information for time allocate to play smartphones and theirs learning methods. Figure 3 shows student information about the time that students are allocating to play smartphones and learning methods that are liked by students. The findings show that 66 students choose to use their smartphones daily in their daily affairs. In addition, the learning method shows that the most popular face-to-face learning method is about 
72 students and the second is to use the smartphone application of 15 students. This finding shows that smartphone-based learning is also an option for students to study Mathematics subjects and this is particularly relevant to the use of the Linear Algebra Gamification Application prototype to learn Linear Algebra topics. Section B is rated using a Likert Scale that has five scales to evaluate all five Prototype Linear Algebra Application prototypes. The five scales are 1: Extremely Disagreeable, 2: Disagree, 3: Undecided, 4: Agree and 5: Strongly Agree. The findings were analyzed using Median and Mod, for each item of gamification. The first gamification item is considered an Experience item, as a whole this item assesses the experience gained from the use of the Linear Algebra Gamification Application. Table 1 shows result for Experience item.

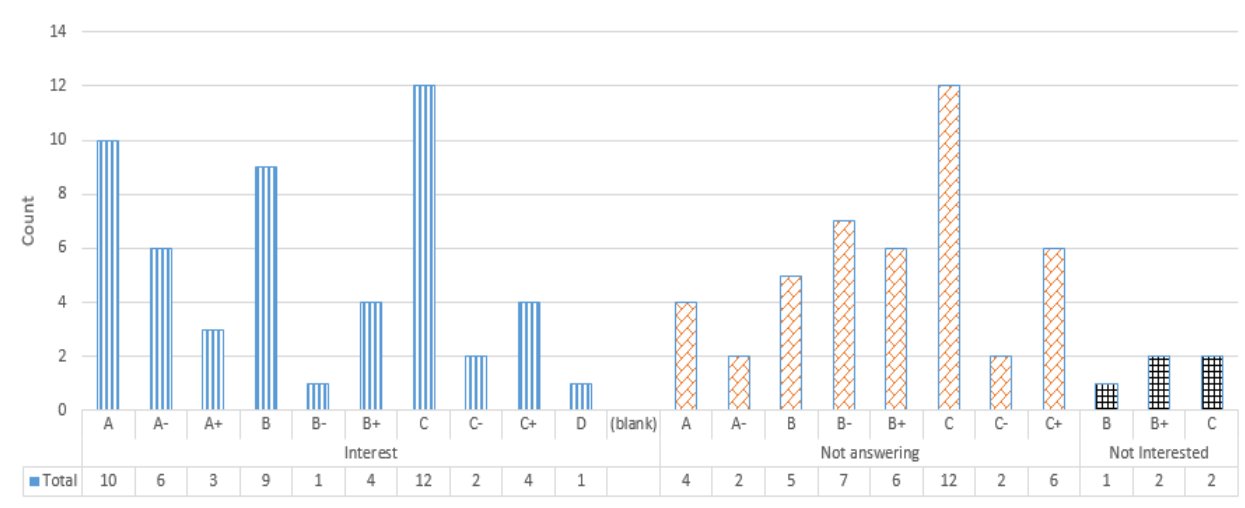

Figure 2. Student information for Mathematics grades their interest in Mathematics

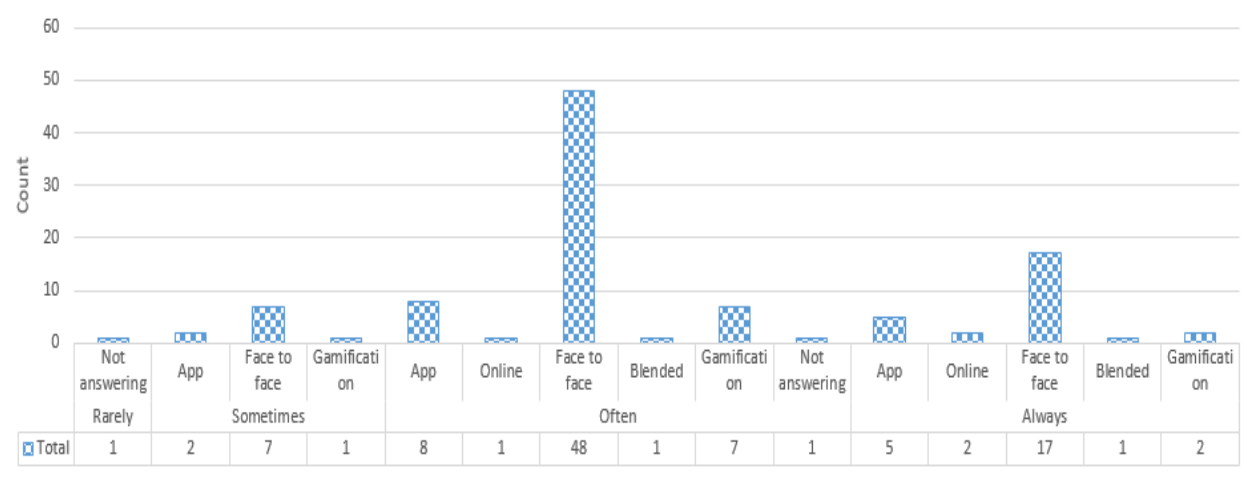

Figure 3. Student information

Table 1. Experience Item

\begin{tabular}{|c|c|c|c|c|c|}
\hline & Item & $\mathrm{N}$ & Median & $\begin{array}{l}\text { Agreed and Strongly } \\
\text { Agreed }\end{array}$ & $\%$ \\
\hline $\mathrm{P} 1$ & $\begin{array}{l}\text { What is your sense of accomplishment after using Linear Algebra } \\
\text { Gamification Application? }\end{array}$ & 104 & 4 & 88 & 84.6 \\
\hline $\mathrm{P} 2$ & $\begin{array}{l}\text { How do you feel after being granted autonomy as a User of Linear Algebra } \\
\text { Gamification? }\end{array}$ & 104 & 4 & 83 & 79.8 \\
\hline P3 & $\begin{array}{l}\text { What are the challenges that Linear Algebra Gamification Apps are suitable } \\
\text { for? }\end{array}$ & 104 & 4 & 90 & 86.5 \\
\hline P4 & How is your delicate level using Linear Algebra Gamification Application? & 104 & 4 & 64 & 61.5 \\
\hline P5 & How are you curiosity to use the Linear Algebra Gamification Application? & 104 & 4 & 98 & 94.2 \\
\hline P6 & $\begin{array}{l}\text { Is learning mastery using Linear Algebra Gamification Application } \\
\text { suitable? }\end{array}$ & 104 & 4 & 77 & 74.0 \\
\hline P7 & $\begin{array}{l}\text { Are there any emotional effects you have learned from Learning Linear } \\
\text { Algebra Gamification? }\end{array}$ & 104 & 4 & 78 & 75.0 \\
\hline P8 & $\begin{array}{l}\text { Can your positive emotions be generated after using Linear Algebra } \\
\text { Gamification Application? }\end{array}$ & 104 & 4 & 86 & 82.7 \\
\hline P9 & Is the purpose of the Linear Algebra Gamification App solved? & 104 & 4 & 84 & 81.0 \\
\hline P10 & $\begin{array}{l}\text { Is the Linear Algebra Gamification Application able to connect you with } \\
\text { other players? }\end{array}$ & 104 & 4 & 80 & 76.9 \\
\hline
\end{tabular}


Table 1 shows the findings of 11 Experiences items. The analysis findings show that the total number of data is 104 with all median items on the scale of four Agree. This shows the majority of students responding to Agree and Strongly Agree to all Experience items. All the items are accomplishment (Agree and Strong Agree=88 and percent=84.6), autonomy (Agree and Strong Agree=83 and percent=79.8), challenges (Agree and Strongly Agree $=90$ and percent=86.5), delicate level (Agree and Strong Agree number=64 and percent=61.5), curiosity (Agree and Strong Agree=98 and percent=94.2), mastery (Agree and Strong Agree=77 and percent=74) emotional effects (number of Agree and Strongly Agree=78 and percent=75), positive emotion (Agree and Strong Agree=86 and percent=82.7), purpose (Agree and Strong Agree $=84$ and percent=81) and Strongly Agree $=80$ and percent=76.9) and connect (Agree and Strong number=78 and percent=75). The overall results of the experience items show that the high percentage of receipts for all 11 items Experience and this show a positive acceptance of the students. The second item is the Gamification Mechanic System. Table 2 shows the findings of the Gamification Mechanic System item.

Table 2 shows the findings for 10 items of the Gamification Mechanic System. The analysis findings show that the total number of data is 104 with all median items on the scale of four Agree. This shows the majority of students responding to Agree and Strongly Agree to all items of the Gamification Mechanic System. All items are reward collection (number Agree and Strong Agree $=83$ and percent=79.8), change in your behavior (Agree and Strong Agree $=86$ and percent=82.7), feedback (Agree and Strong Agree=70 and percent=76.3), rule (Agree and Strong Agree=69 and percent=66.3), knowledge (Agree and Strong Agree=87 and percent=83.4), work harder (Agree and Strongly Agree=86 and percent=82.7), storytelling (Agree and Strong Agree=86 and percent=82.7), unexpected surprises and losses (Agree and Strong Agree=78 and percent=75), time pressures (Agree and Strongly Agree=83 and percent=79.8), and variables (Agree and Strong Agree=81 and percent=77.9). The overall results of the Gamification Mechanic System items show, the high percentage of acceptance for all 10 Items of the Gamification Mechanic System and this shows a positive acceptance of the students. Table 3 shows the findings of Reward items.

Table 2. Gamification Mechanic System Item

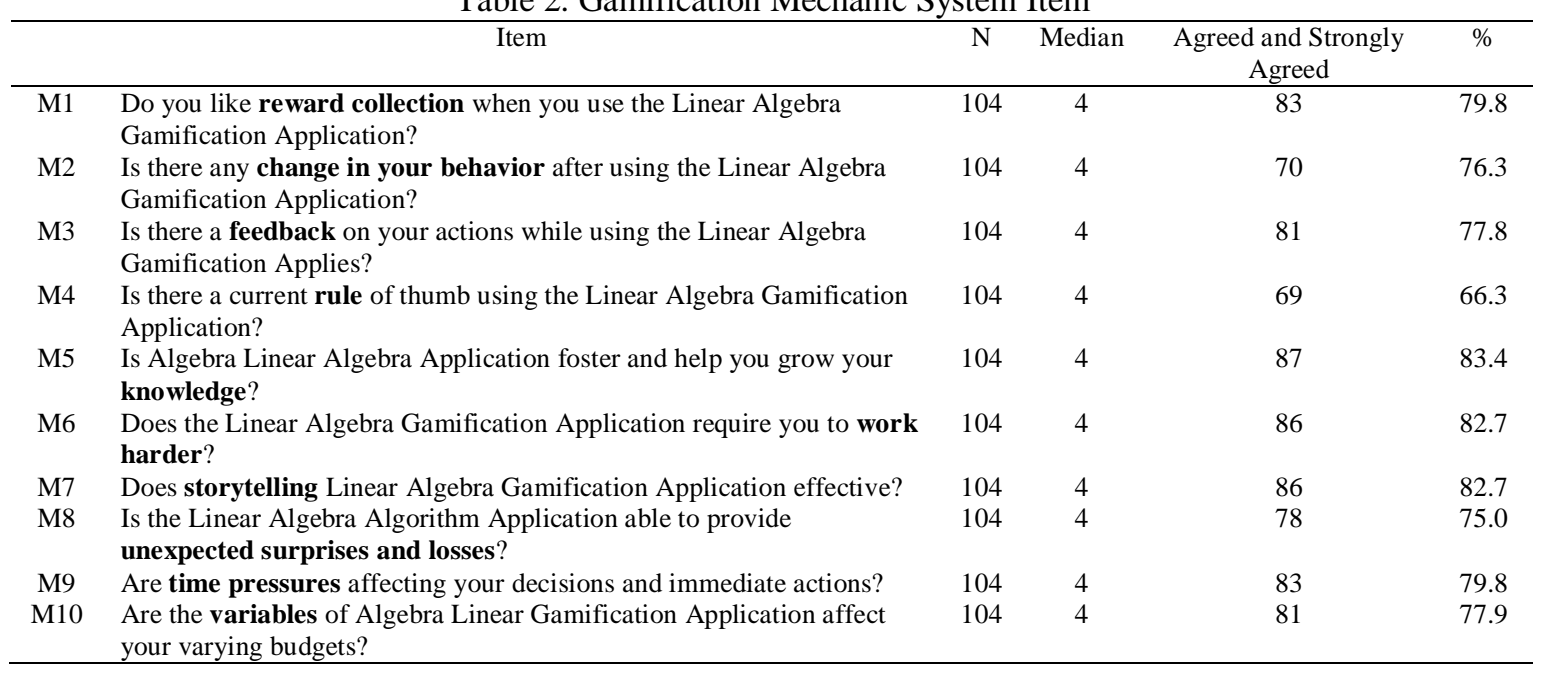

Table 3 shows the findings of seven reward items. The analysis findings show that the total number of data is 104 with all median items on the scale of four Agree. This shows the majority of students responding to Agree and Strongly Agree to all Reward items. All items are reward (Agree and Strong Agree number=86 and percent=82.7), tangible rewards (Agree and Strongly Agree=69 and percent=66.3), unreal rewards (Agree and Strong Agree number=68 and percentage=65.4), communicate (Agree and Strong Agree $=85$ and percent=81.7), points (Agree and Strongly Agree $=90$ and percent=86.5), level of difficulty (Agree and Strong Agree=83 and percent=79.8), and badges and achievements (Agree and Strong Agree $=89$ and percent=85.6). The overall outcome of the Reward item shows that the high percentage of receipts for all seven Rewards and this shows a positive acceptance of the students. Table 4 shows the findings of the Goal item. 
Table 3. Reward Items

\begin{tabular}{|c|c|c|c|c|c|}
\hline & Item & $\mathrm{N}$ & Median & $\begin{array}{l}\text { Agreed and Strongly } \\
\text { Agreed }\end{array}$ & $\%$ \\
\hline G1 & $\begin{array}{l}\text { Do you like the rewards given when you use the Linear } \\
\text { Algebra Gamification Application? }\end{array}$ & 104 & 4 & 86 & 82.7 \\
\hline G2 & $\begin{array}{l}\text { Do you get tangible rewards from Algebra Linear } \\
\text { Gamification App? }\end{array}$ & 104 & 4 & 69 & 66.3 \\
\hline G3 & $\begin{array}{l}\text { Do you like the unreal rewards of Linear Algebra } \\
\text { Gamification Applications? }\end{array}$ & 104 & 4 & 68 & 65.4 \\
\hline G4 & $\begin{array}{l}\text { Can you communicate about your progress in playing Linear } \\
\text { Algebra Gamification Apps? }\end{array}$ & 104 & 4 & 85 & 81.7 \\
\hline G5 & $\begin{array}{l}\text { Do you like points in Linear Algebra Gamification } \\
\text { Application? }\end{array}$ & 104 & 4 & 90 & 86.5 \\
\hline G6 & $\begin{array}{l}\text { Do you like the level of difficulty available in the Linear } \\
\text { Algebra Gamification Application? }\end{array}$ & 104 & 4 & 83 & 79.8 \\
\hline G7 & $\begin{array}{l}\text { Do you like the badges and achievements for the Linear } \\
\text { Algebra Gamification Application? }\end{array}$ & 104 & 4 & 89 & 85.6 \\
\hline
\end{tabular}

Table 4 shows the findings for three Goal items. The analysis findings show that the total number of data is 104 with all median items on the scale of four Agree. This shows that the majority of students answer Agree and Strongly Agree to all Goal items. All of these items are, goal (Agree and Strong Agree number $=87$ and percent=83.7), challenge/quest/mission/task (Agree and Strong Agree $=82$ and percent=78.8) and appreciation (Agree and Strongly Agree $=87$ and percent=83.7). The overall results of the Goal items show, the high percentage of acceptance for all three Goal items and this indicates a positive acceptance of the students. Table 5 shows the findings for Social items.

Table 4. Result for Goal Item

\begin{tabular}{|c|c|c|c|c|c|}
\hline & Item & $\mathrm{N}$ & Median & $\begin{array}{l}\text { Agreed and Strongly } \\
\text { Agreed } \\
\end{array}$ & $\%$ \\
\hline $\mathrm{T} 1$ & Is your goal playing Linear Algebra Gamification Application clear? & 104 & 4 & 87 & 83.7 \\
\hline $\mathrm{T} 2$ & $\begin{array}{l}\text { Do you like the challenges/quest/missions/tasks available on Linear Algebra } \\
\text { Gamification Application? }\end{array}$ & 104 & 4 & 82 & 78.8 \\
\hline $\mathrm{T} 3$ & Does Algebra Linear Application Alert appreciate you on a completed task? & 104 & 4 & 87 & 83.7 \\
\hline
\end{tabular}

Table 5 shows the findings for seven Social Items. The analysis findings show that the total number of data is 104 with all median items on the scale of four Agree. This shows the majority of students responding to Agree and Strongly Agree to all Social items. All of these items are competition (Agree and Strong Agree number=87 and percent=83.7), leaderboard (Agree and Strongly Agree=82 and percent=78.8), incentives and cooperation (Agree and Strong Agree=65 and percent=62.5), group (Agree and Strong Agree $=76$ and percent $=73$ ), fame (Agree and Strong Agree $=71$ and percent $=68.3$ ), keep playing (Agree and Strong Agree $=82$ and percent=78.8), and social features (Agree and Strong Agree $=83$ and percent=79.8). The overall outcome of Social items shows that the high percentage of receipts for all seven Social items and this indicates positive acceptance of the students.

Table 5. Result for Social Items

\begin{tabular}{|c|c|c|c|c|c|}
\hline & Item & $\mathrm{N}$ & Median & $\begin{array}{l}\text { Agreed and Strongly } \\
\text { Agreed }\end{array}$ & $\%$ \\
\hline S1 & Do you like your competition with other players? & 104 & 4 & 87 & 83.7 \\
\hline $\mathrm{S} 2$ & Do you like the leaderboards available on Linear Algebra Gamification Apps? & 104 & 4 & 82 & 78.8 \\
\hline S3 & $\begin{array}{l}\text { Do you like the incentives and cooperation provided in Linear Algebra } \\
\text { Gamification Applies? }\end{array}$ & 104 & 4 & 65 & 62.5 \\
\hline S4 & Is Linear Algebra Gamification application playable in groups? & 104 & 4 & 76 & 73.0 \\
\hline S5 & $\begin{array}{l}\text { Are you able to gain fame or attention from the game of Linear Algebra } \\
\text { Gamification Application? }\end{array}$ & 104 & 4 & 71 & 68.3 \\
\hline S6 & $\begin{array}{l}\text { Are the social features available on Linear Algebra Gamification Apps help } \\
\text { push or pull you to keep playing? }\end{array}$ & 104 & 4 & 82 & 78.8 \\
\hline S7 & $\begin{array}{l}\text { Do you like other social features that exist in the Linear Algebra Gamification } \\
\text { Application? }\end{array}$ & 104 & 4 & 83 & 79.8 \\
\hline
\end{tabular}




\section{DISCUSSION}

The findings of the five items surveyed showed that the acceptance of the prototype of the Linear Algebra Gamification Application was very encouraging from a total of 104 students. This is because all 38 questions for the five items earn a median of four and this indicates the majority of students choose "Agree" and "Strongly Agree". The findings also show the percent "Agree" and "Strongly Agree" for all questions having a high percentage of between 61.5 and 94.2. This shows more than half satisfied and likes to use the Linear Algebra Gamification Application prototype.

\section{CONCLUSION}

This study presents evaluation effectiveness of learning Linear Algebra using gamification strategy. By learning Linear Algebra using gamification can help make learning process become more interesting, fun and motivated. Evaluation was carried out for 174 students in Polytechnic Kota Kinabalu and students were divided into two group which is Gamification and Traditional category learning. The findings showed that the Gamification had $84.6 \%$ students successfully fulfilled both positive learning conditions there was an increase in pre-test post-test score and learning process was done within two minutes and above while the Traditional category learning had $77.1 \%$ students positive learning.

\section{ACKNOWLEDGEMENTS}

Researchers are thankful to Universiti Malaysia Sabah (UMS) for the support of the resources and necessary facilities for the preparation of the research. This study is currently funded by a UMSGreat Grant from Universiti Malaysia Sabah (GUG0301-2/2018).

\section{REFERENCES}

[1] S.Nurul, M.Mohamad, S.Salam, and N. Bakar, An Analysis of Gamification Elements in Online Learning To Enhance Learning Engagement. ICOCI Kuala Lumpur. Universiti Utara Malaysia, (041), 2017, pp. 25-27. Retrieved from http://icoci.cms.net.my/PROCEEDINGS/2017/Pdf_Version_Chap09e/PID41-452-460e.pdf.

[2] K. Kapp, The Gamification of Learning and Instruction, Pfeiffer. San Francisco, 2012, pp. 480. https://doi.org/10.4018/jgcms.2012100106

[3] S.Villagrasa, D.Fonseca, E.Redondo, and J. Duran, Teaching Case of Gamification and Visual Technologies for Education. Journal of Cases on Information Technology, 16(4), 2014, pp. 38-57.

[4] J.Morey, J.Gammack, and E.Thornquist, Gamifying Foundational STEM Skills. Proceedings-Asia-Pacific World Congress on Computer Science and Engineering 2016 and Asia-Pacific World Congress on Engineering 2016, APWC on CSE/APWCE 2016, 2017, pp. 164-170. https://doi.org/10.1109/APWC-on-CSE.2016.036

[5] M.Gasah, N.H.M.Zain, and A.Baharum, An approach in creating positive emotion for children's e-learning based on user interface design. Indones J Electr Eng Comput Sci., 2019, 13(3), pp. 1267-73.

[6] Y.Heryadi, and K.Muliamin, Gamification of M-learning Mandarin as second language. 2016 1st International Conference on Game, Game Art, and Gamification, ICGGAG 2016, 2017, https://doi.org/10.1109/ICGGAG.2016.8052645

[7] S.N.W.Shamsuddin, M.F.Selman, I.Ismail, M.M.Amin, and N.A.Rawi, A conceptual framework for gamified learning management system for LINUS students. Indones J Electr Eng Comput Sci., 2018, 12(3), pp. 1380-5.

[8] T.Jagušt, I.Boticki, and V.Mornar, Gamified Digital Math Lessons for Lower Primary School Students, 2017, https://doi.org/10.1109/IIAI-AAI.2017.17

[9] F.F.Lubis, Y.Rosmansyah, and S.H.Supangkat, Math Workout Series: Enhancing Learning Application with Gamification, (November), 2014, pp. 24-27.

[10] J.M.Koivisto, L.Hannula, R.B.Bøje, S.Prescott, A.Bland, L.Rekola, and P. Haho, Design-based research in designing the model for educating simulation facilitators. Nurse Education in Practice, 29(December 2016), 2018, pp. 206-211. https://doi.org/10.1016/j.nepr.2018.02.002

[11] J.Baldeon, A.Puig, I.R.Santiago, and M.Lopes-Sanchez, Gamification of Elementary Math Learning: a Game Designer Role-Playing Experience With Kids. II Int Work Gamification Educ gEducation 2015. 2015; (February 2017).

[12] D.Kuswardhana, S.Hasegawa, and J.Juhanaini. The instructional thematic game for children with mild mental retardation: For enhancement of left-right recognition skill. Int J Electr Comput Eng., 2017, 7(1), pp. 469-78.

[13] R.M.G.Garcia-castelan, L.Margarita, and M.Herrera, CocoGame: A funny app to learn physics and math. 2017;(October)

[14] T.Walter, S.Eichwald, N.Klaas, J.Reder, and W.Muller, RefugeeScout: Learning German Culture for a Better Integration with a Storytelling Application. Proceedings-IEEE 17th International Conference on Advanced Learning Technologies, ICALT 2017, 2017, pp. 95-97. https://doi.org/10.1109/ICALT.2017.143

[15] W.S.Yue, and C.Y.Ying, The Evaluation Study of Gamification Approach in Malaysian History Learning via Mobile Game Application. Proceedings-IEEE 17th International Conference on Advanced Learning Technologies, ICALT 2017, 2017, pp. 150-152. https://doi.org/10.1109/ICALT.2017.69. 
[16] M.Romero, Work, Games and Lifelong Learning in the 21st Century. Procedia-Soc Behav Sci [Internet]. 2015;174, pp. 115-21. Available from: http://linkinghub.elsevier.com/retrieve/pii/S1877042815006850

[17] N.Pheeraphan, Enhancement of the 21st Century Skills for Thai Higher Education by Integration of ICT in Classroom. Procedia-Soc Behav Sci [Internet]. 2013;103, pp. 365-73. Available from: http://linkinghub.elsevier.com/retrieve/pii/S1877042813037919

[18] D.Rai, and J.E.Beck, Math Learning Environment with Game-Like Elements. Int J Game-Based Learn [Internet]. 2012;2(2), pp. 90-110. Available http://services.igiglobal.com/resolvedoi/resolve.aspx?doi=10.4018/ijgbl.2012040106

[19] F.F.Lubis, Y.Rosmansyah, S.H.Supangkat. Math Workout Series: Enhancing Learning Application with Gamification. 2014;(November), pp. 24-7.

[20] G.Harel, The learning and teaching of linear algebra: Observations and generalizations. J Math Behav [Internet]. 2017;46, pp. 69-95. Available from: http://dx.doi.org/10.1016/j.jmathb.2017.02.007

[21] Z.A.Norshikin, B.Aslina, S.M.F.S.M.Dardin, N.S.A.Fatah, I.Ismail, N.M.M.Yusop, Designing Engaging Community Learning Application with Children Using Gamification, International Journal of Engineering \& Technology, 7 (4.31), 2018, pp. 491-498.

[22] H.Dogan, Differing instructional modalities and cognitive structures: Linear algebra. Linear Algebra Appl [Internet]. 2017;542, pp. 464-83. Available from: http://dx.doi.org/10.1016/j.laa.2017.07.007

[23] J.Boaler, and T.Sengupta-Irving, The many colors of algebra: The impact of equity focused teaching upon student learning and engagement. J Math Behav [Internet]. 2016;41, pp. 179-90. Available from: http://dx.doi.org/10.1016/j.jmathb.2015.10.007

[24] A.Rattan, C.Good, C.S.Dweck, "It's ok-Not everyone can be good at math": Instructors with an entity theory comfort (and demotivate) students. J Exp Soc Psychol [Internet]. 2012;48(3), pp. 731-7. Available from: http://dx.doi.org/10.1016/j.jesp.2011.12.012

[25] J.Broer, The Gamification Inventory An Instrument for the Qualitative Evaluation of Gamification and its Application to Learning Management Systems, (Jan), 2017. 